\title{
Effect of vacuum on porosity and mechanical properties of high-pressure die-cast pure copper
}

\author{
Hong-mei Yang ${ }^{1,2,3}$, Zhi-peng Guo ${ }^{1,2}$, Hua-zhongYang ${ }^{3}$, Zhi-hua Fu ${ }^{3}$, Zhou-meng Pu ${ }^{3}$, ${ }^{*}$ Shou-mei Xiong ${ }^{1,2}$ \\ 1. School of Materials Science and Engineering, Tsinghua University, Beijing 100084, China \\ 2. Key Laboratory for Advanced Materials Processing Technology, Ministry of Education, Beijing 100084, China \\ 3. Yunnan Copper Die-casting Technology Co., Ltd., Kunming 650001, China
}

\begin{abstract}
Pure copper tensile bars were produced by conventional die casting (HPDC) and vacuum-assist die casting (VADC) processes. Porosity and mechanical properties were investigated by using optical microscopy (OM), scanning electron microscopy (SEM), energy dispersive spectroscopy (EDS), X-ray computed tomography (XCT) and tensile tester. Results show that porosities including gas porosity and shrinkage porosity could be observed in copper castings. Since the application of vacuum could reduce filling related gas entrapment and facilitate solidification due to the increased heat transfer between metal and die, both number and size of the entrapped gases, as well as shrinkage porosities were significantly reduced in vacuum-assist die castings of pure copper. The porosity fraction decreased from $2.243 \%$ to $0.875 \%$ compared with that of the conventional die casting. Besides, mechanical properties were improved significantly, i.e., by $15 \%$ for ultimate tensile strength and three times for elongation.
\end{abstract}

Key words: vacuum; copper; high pressure die casting (HPDC); mechanical properties; porosity

CLC numbers: TG146.1 1 Document code: $\mathrm{A}$

Article ID: 1672-6421(2019)04-232-06

$\mathrm{P}$ ure copper rotors are widely used in industry because of high electrical conductivity and thermal conductivity. Comparing with those rotors manufactured using aluminum alloys ${ }^{[1-3]}$, energy efficiency could be increased by $1 \%-7 \%$ when copper rotors are used. Liang et al. ${ }^{[4]}$ reported that copper rotor motors provide a costeffective way for meeting the new high-efficiency IE3 and IE4 standards.

High pressure die casting (HPDC) is one of the most efficient processes for the mass production of pure copper rotors. However, porosity normally exists in the products, which greatly reduces the mechanical properties of the casting. Brush et al. ${ }^{[5]}$ found that the microstructure of a HPDC copper rotor invariably contained shrinkage porosity and gas/film entrapment. Porosity appeared mostly in the internal region of the end ring rather than in the conductor bars. The porosity area fraction in the middle of the end ring was $2 \%-3 \%$ for small rotors, and $8 \%-10 \%$ for larger rotors. They found that a higher pouring temperature (approximately $1,465^{\circ} \mathrm{C}$ ) could reduce porosity.

\section{*Shou-mei Xiong}

Male, Ph. D. Professor. Research interests: Al and Mg alloys high pressure die casting and microstructure simulation during solidification.

E-mail: smxiong@tsinghua.edu.cn

Received: 2019-03-13; Accepted: 2019-05-22
To achieve high rotational speed, e.g., 10,000-20,000 rpm, both electrical conductivity and strength need to increase for copper motors. Bárdos et al. ${ }^{[6]}$ investigated the stress distribution of a rotor under different rotational speeds and found that the mechanical stress of the blade (outer diameter was $190 \mathrm{~mm}$ ) increased from $9 \mathrm{MPa}$ to $30 \mathrm{MPa}$ when the applied speed increased from 3,600 $\mathrm{rpm}$ to $10,000 \mathrm{rpm}$. Besides, the micro-porosity did not cause motor failure if the surface speed and rotor operating temperature were lower than $100 \mathrm{~m} \cdot \mathrm{s}^{-1}$ and $200{ }^{\circ} \mathrm{C}$, respectively.

Porosity is an important factor that influences mechanical properties of the component. According to Lee et al. ${ }^{[7,8]}$, the material ductility was highly dependent on the local porosity fraction. $\mathrm{Li}$ et al. ${ }^{[9]}$ characterized the porosity of conventional die castings of AM 60B magnesium alloy using X-ray tomography and found that the gas shrinkage pore and netshrinkage were shown to be vital for crack initiation. As investigated by Song et al. ${ }^{[10,11]}$, the existence of porosity was detrimental to the mechanical properties of magnesium alloys. Biswas et al. ${ }^{[12]}$ studied the influence of porosity on mechanical properties of the HPDCAZ91 alloy, and found both the elongation and fracture stress were dependent on the porosity fraction.

Vacuum-assist die casting (VADC) is applied to reduce gas porosity for aluminum and magnesium 
alloys $^{[13-15]}$. The application of vacuum in high pressure die casting can significantly reduce the air in both shot sleeve and die cavity. The reduced gas pressure in the die cavity can avoid most of the gas entrapment and improve the melt filling, which improves both tightness and mechanical properties of castings. The volume of gas porosity and the pore size in the casting are significantly reduced using VADC. Besides, mechanical properties, including the tensile strength and ductility, were improved significantly. Li et al. ${ }^{[16]}$ studied the effect of a flow distributor on VADC magnesium alloys. Comparing with conventional HPDC, the application of vacuum, together with a specially designed flow distributor, could significantly reduce the gas pores by $\sim 90 \%$ and externally solidified crystals (ESCs) by $80 \%$.

However, existing studies on vacuum-assist die casting (VADC) copper are very limited. In this study, the effect of vacuum on porosity and mechanical properties of pure copper die-castings were investigated. Quantitative analysis on microstructure patterns, tensile strength and fracture mechanism were performed for both conventional HPDC and VADC specimen. $\mathrm{X}$-ray computed tomography (XCT) was used to characterize the 3-D morphology of the porosity.

\section{Experimental procedure}

During the experiment, a specific casting (Fig. 1) was produced by a Buhler die casting machine equipped with a vacuum system. The vacuum pressure in the die cavity was measured by a similar vacuum system as that reported by Wang and $\mathrm{Xiong}^{[17]}$. The casting material was oxygen free copper rods (99.97wt.\% pure copper). The oxygen content of the casting after HPDC varied from 0.15 wt.\% to 0.2 wt.\% which was analyzed using a LECO RO500 oxygen determinator. During die casting experiments, the pouring temperature was 1,300 ${ }^{\circ} \mathrm{C}$, slow shot speed was $0.8 \mathrm{~m} \cdot \mathrm{s}^{-1}$, fast shot speed was $3 \mathrm{~m} \cdot \mathrm{s}^{-1}$, and the pre-heating temperature for the die was $200{ }^{\circ} \mathrm{C}$. Both conventional HPDC and VADC were performed to produce

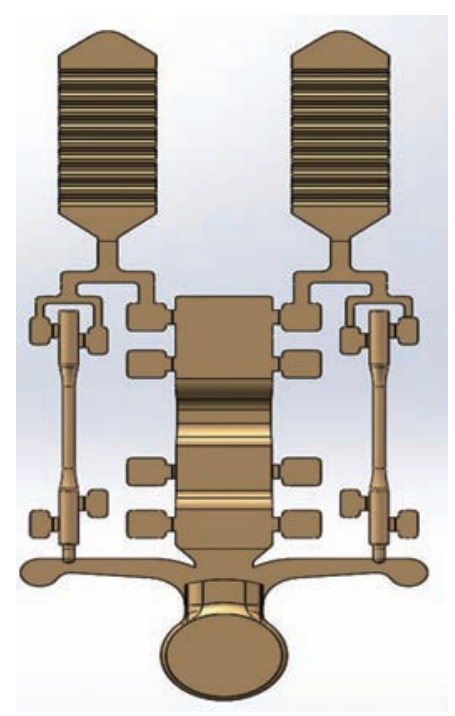

Fig. 1: Configuration of specific casting including two tensile test bars two standard tensile testing specimens for each die casting shot, of which one was for tensile testing and the other was for microstructure and porosity characterization.

The volume fraction of the porosity was measured according to Archimedes' principle with a gas expansion displacement method. Gauge samples $(50 \mathrm{~mm})$ were extracted from the tensile bars, weight of which was measured using a BSM220.4 electronic balance with an accuracy of $\pm 0.1 \mathrm{mg}$. The volume was measured using a HX-TD true density tester with an accuracy of $0.0001 \mathrm{~cm}^{3}$. The volume fraction of the porosity was determined based on:

$$
\begin{gathered}
P \%=\left(\frac{\rho_{\mathrm{th}}-\rho_{\mathrm{td}}}{\rho_{\mathrm{th}}}\right) \cdot 100 \% \\
\rho_{\mathrm{td}}=M / V
\end{gathered}
$$

where $M$ is the mass, $V$ is the volume, $\rho_{\mathrm{td}}$ is the measured density, and $\rho_{\text {th }}$ is the theoretical density $\left(8.94 \mathrm{~g} \cdot \mathrm{cm}^{-3}\right)$.

Samples for quantitative analysis were extracted from the specimen after the density measurement. The specimens were ground to 2,000 grit, polished with a $0.5 \mu \mathrm{m}$ colloidal silica suspension, and then etched with a solution of $8 \mathrm{~g} \mathrm{FeCl}_{3} \cdot 5 \mathrm{H}_{2} \mathrm{O}$, $50 \mathrm{ml} \mathrm{HCl}$ and $100 \mathrm{ml} \mathrm{H}_{2} \mathrm{O}$. The microstructure of the samples was taken from as-polished surface using a ZEISS optical microscope (OM) and scanning electron microscope (SEM) equipped with an energy dispersive spectroscope (EDS).

For X-ray tomography inspection, samples of $\Phi 3 \mathrm{~mm} \times 15 \mathrm{~mm}$ were machined from the center of tensile samples, and scanned using a phoenix Nanotomm (manufactured by General Electric) X-ray tomography equipment. Quantitative measurements of the porosity, including volume, surface area and sphericity were then obtained using VG Studio Max 3.0 software. The sphericity $(S p h)$ is defined as ${ }^{[18]}$ :

$$
S p h=\frac{\pi \times\left(D_{\mathrm{v} \text { eq }}\right)^{2}}{s}
$$

where $D_{\text {veq }}$ is the equivalent diameter of the porosity and $S$ is the surface area of the porosity. The sphericity ranges from 0 to 1 , with 1 indicating a perfect sphere. Shrinkage porosity tends to have a lower sphericity than gas porosity. The applied voltage and current in the tube were $110 \mathrm{kV}$ and $130 \mu \mathrm{A}$, respectively. The pixel size was $2.5 \mu \mathrm{m}$.

The tensile tests were performed using a WDW-3020 testing machine with a strain rate of $2 \mathrm{~mm} \cdot \mathrm{min}^{-1}$. The tensile testing specimen had a length of $120 \mathrm{~mm}$, a gauge length of $50 \mathrm{~mm}$, and a gauge diameter of $6.4 \mathrm{~mm}$ (Fig. 1). The fracture surface of the tensile specimen was observed using SEM.

\section{Results and discussion}

Figure 2 shows the as-polished morphologies of the porosities in the center region of the specimen with and without vacuum. Under conventional HPDC, gas porosity and shrinkage porosity exhibit different morphologies (Fig. 2a). Comparing with shrinkage porosity, the gas porosity was more spherical. Figure 

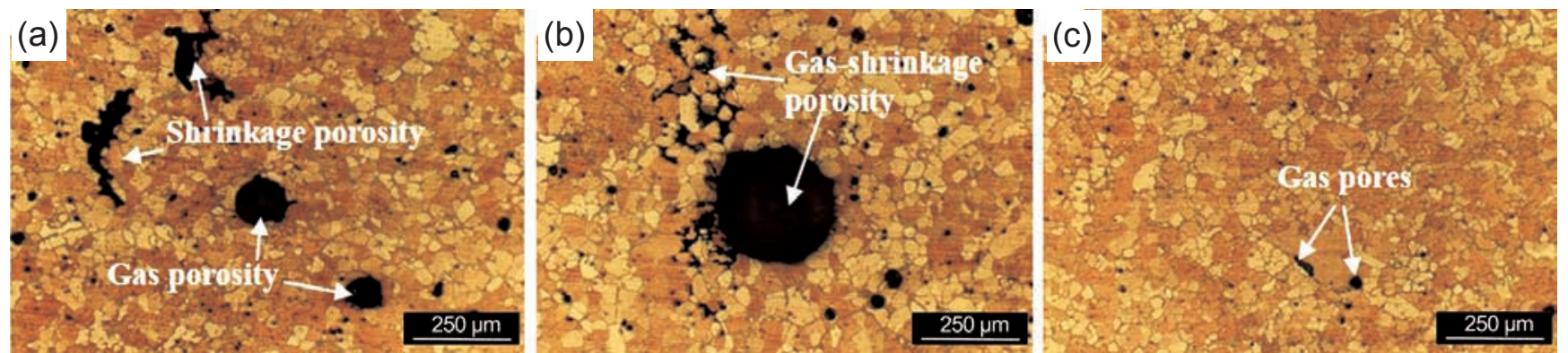

Fig. 2: Optical microscopy images of center regions for conventional HPDC (a, b) and VADC (c)

2(b) shows a large gas pore surrounded by smaller shrinkage porosities. This porosity was identified as gas shrinkage by Lee and Gokhal ${ }^{[19]}$. The existence of gas porosity could induce the formation of shrinkage. The gas porosity was surrounded by shrinkage pores because the air in gas pores was an efficient heat-insulation medium that retarded heat transfer. Porosity also exhibited in the VADC specimen, but the number and size greatly decreased (Fig. 2c).

Figure 3 shows the morphology and EDS spectra at the internal surface of the porosity in conventional HPDC. Table 1 shows the element composition at the internal surface of porosity. Figure 3(a) shows that the gas porosity had a regular round shape and smooth internal surfaces. Oxygen content of 0.82 wt.\% (Table 1) was detected in the internal surface of the gas porosity by EDS (Fig. 3d). Figure 3(b) shows that the shrinkage porosity was irregular in morphology and surrounded by primary $\alpha$-Cu grains. The element composition at the internal surface of the shrinkage indicated the existence of $\mathrm{Cu}$ element (Fig. 3e). Figure 3(c) shows another type of shrinkage porosity of $100 \mu \mathrm{m}$ with a similar shape and rough internal surfaces. Figure 3(f) shows the composition at the internal surface of the shrinkage. The oxygen concentration was 2.89 wt.\% (Table 1), which was higher than that in the gas porosity. The gas porosity was covered by the eutectic $\left(\mathrm{Cu}+\mathrm{Cu}_{2} \mathrm{O}\right)$ which formed at a later stage of solidification.
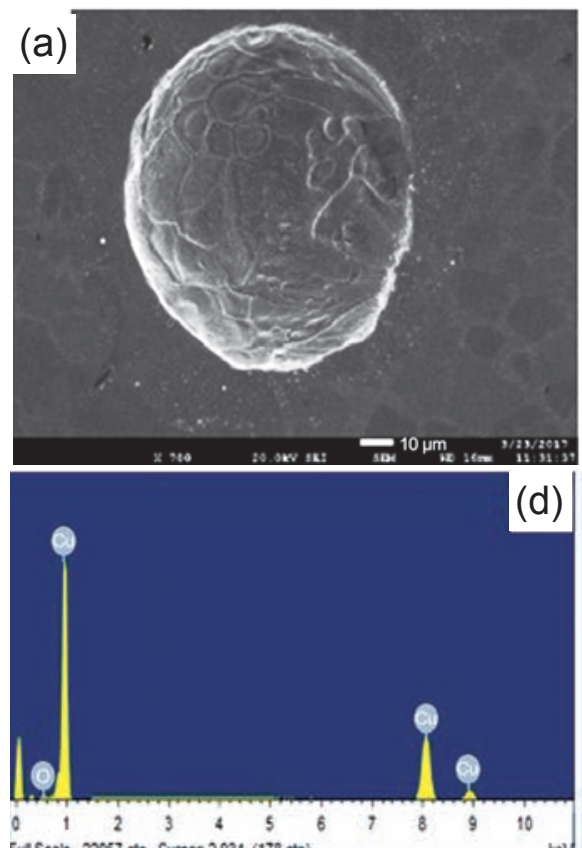

(d)
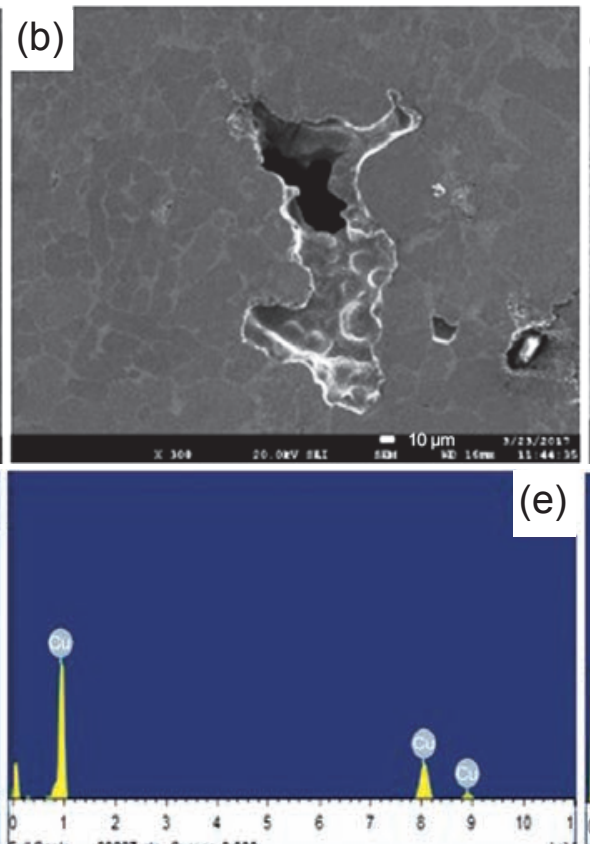
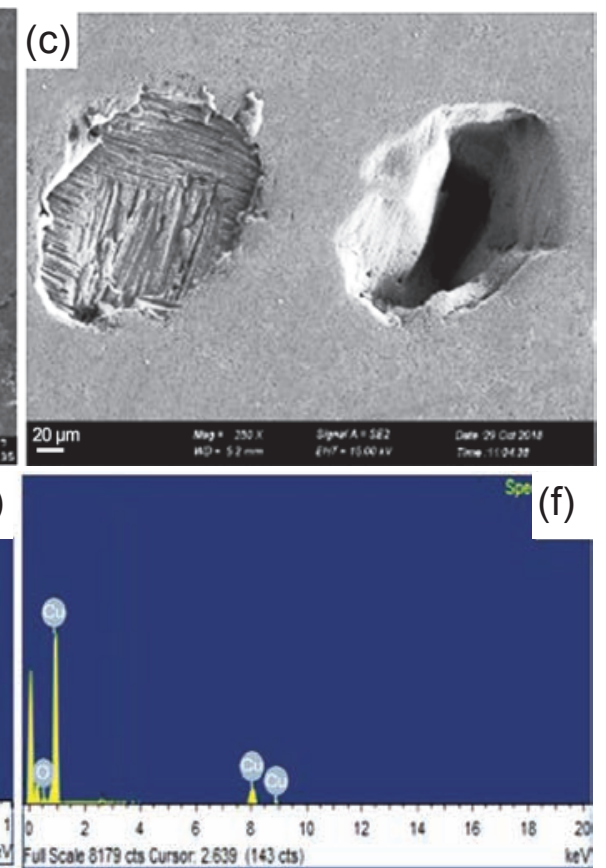

Fig. 3: Typical SEM micrographs and EDS spectra at internal surface of porosities in conventional HPDC: (a, d) gas pore; (b,c, e, f) two kinds of shrinkage porosities

Table 1: EDS spectra of three types of porosity (wt. \%)

\begin{tabular}{cccc} 
Element & Gas pore & $\begin{array}{c}\text { Shrinkage in } \\
\text { Fig. } \mathbf{3 ( b )}\end{array}$ & $\begin{array}{c}\text { Shrinkage in } \\
\text { Fig. 3(c) }\end{array}$ \\
\hline O K & 0.82 & 0 & 2.89 \\
Cu L & 99.18 & 100.00 & 97.11 \\
Totals & 100.00 & 100.00 & 100.00
\end{tabular}

Figure 4 shows the 3-D morphology of the porosity obtained by X-ray tomography. Under conventional HPDC, the porosity was distributed throughout the whole specimen. However, the porosity was more concentrated in the center region of the specimen under VADC. The porosity number was 3,015 in conventional HPDC and 495 in VADC. Comparing with the conventional die casting, application of the vacuum could reduce the porosity number and the volume of the largest 


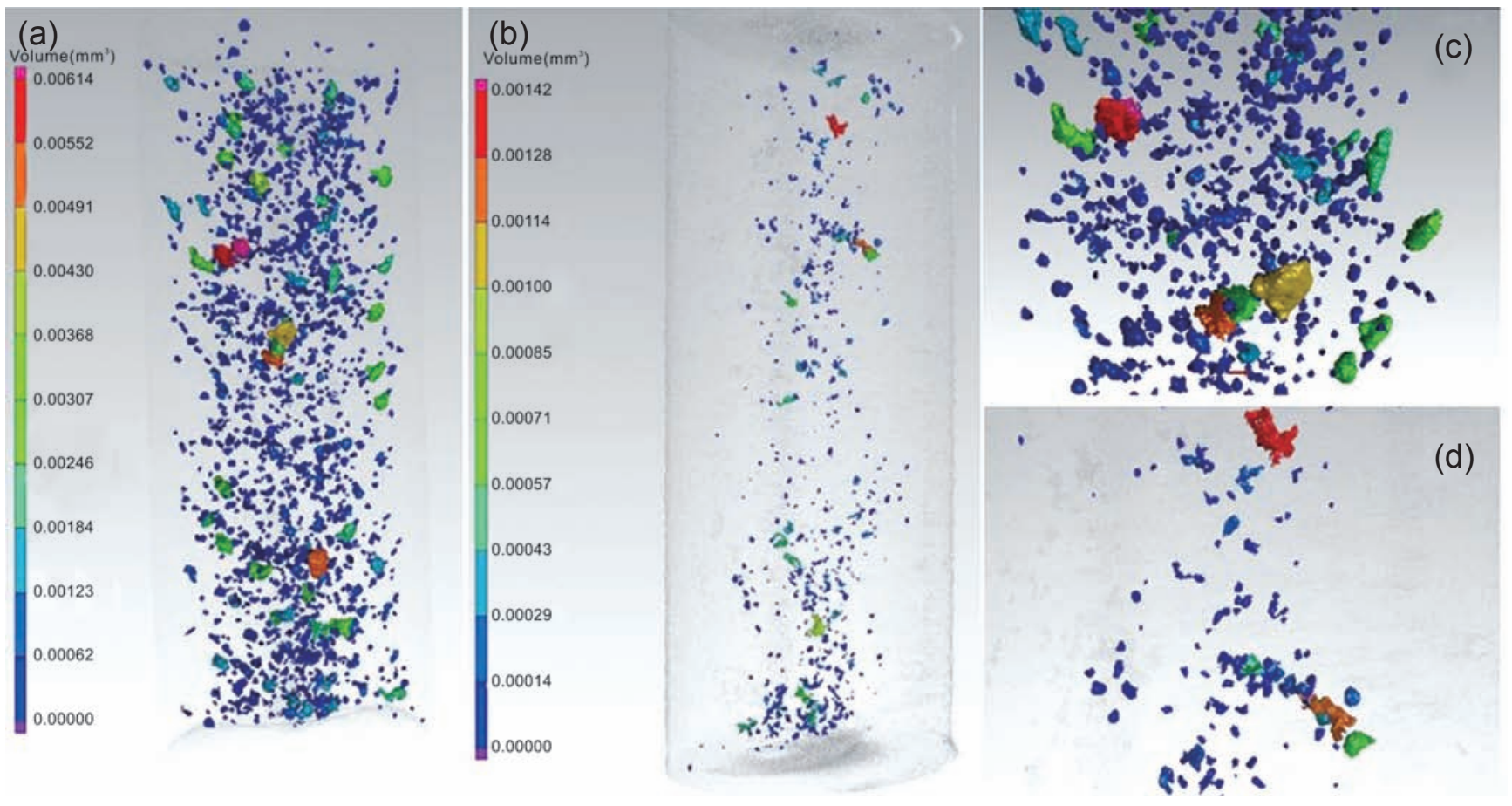

Fig. 4: Visual representation of macro-pores using X-ray tomography: (a, c) Conventional HPDC, (b, d) VADC

porosity by $\sim 84 \%$ and $\sim 90 \%$, respectively. The pore size under conventional HPDC was $38-765 \mu \mathrm{m}$ and that in VADC was 21-339 $\mu \mathrm{m}$. Figure 5 shows the existence of 3D morphology of porosities in copper casting, including gas porosity, gas shrinkage, and shrinkage porosity. The sphericity of gas pore was higher than 0.5 , while it was lower for net shrinkage, island shrinkage and gas shrinkage [Fig. 5(b)], which agreed well with results found by Yang et al. ${ }^{[18]}$.
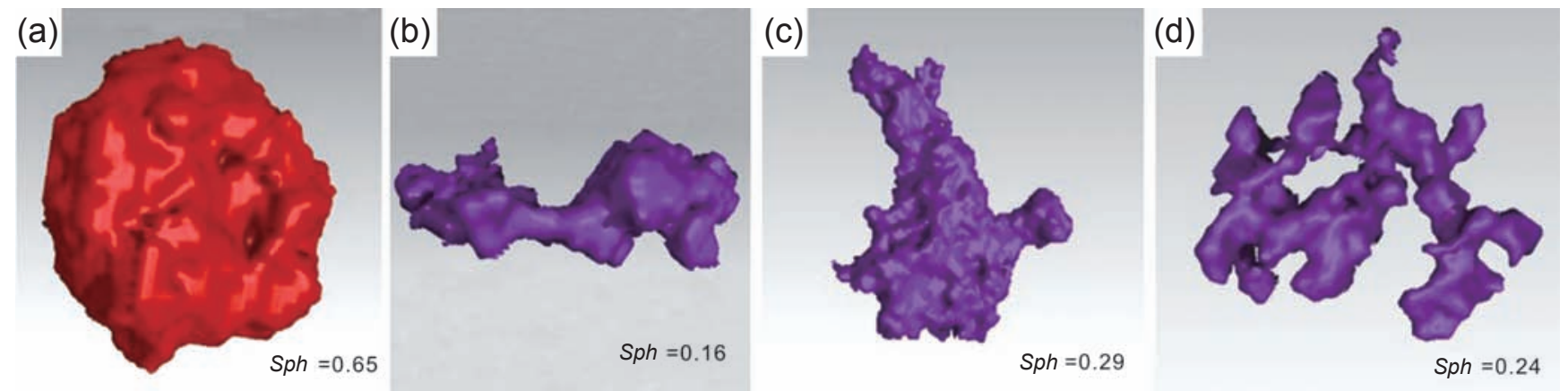

Fig. 5: 3D morphology of four types of porosities: (a) gas porosity, (b) gas shrinkage, (c) and (d) shrinkage porosity

Figure 6 shows porosity sphericity versus diameter. It is clear that the more than $75 \%$ of porosity had a sphericity greater than 0.5 , i.e., gas porosity. The gas porosity in the casting was not eliminated even when the vacuum was applied. This is caused by the relatively low vacuum level in the die cavity. $\mathrm{Cao}^{[20]}$ found that the application of vacuum could significantly decrease the average porosity size. Both tensile strength and elongation were improved as the absolute pressure decreased in the die cavity.

In this work, the vacuum level in the die cavity was $\sim 80$ mbar during casting. The application of the vacuum in HPDC could greatly reduce both the number and size of gas porosity as well as the shrinkage porosity. In addition, the shrinkage porosity with a sphericity of $<0.5$, as well as gas shrinkage, was significantly reduced. Reducing the amount of entrapped gas using VADC could significantly reduce the gas shrinkage as well as the other shrinkage porosity. Besides, the volume fraction of the porosity was $2.243 \%$ for conventional HPDC and $0.875 \%$ for VADC. The application of vacuum significantly decreased the volume fraction of the porosity.

Figure 7 shows the tensile testing results. With vacuum, the ultimate tensile strength (UTS) increased from 187.9 to 215.8 $\mathrm{MPa}$, and the elongation increased from $13.5 \%$ to $36.1 \%$. The yield strength (YS) increased slightly from 47.8 to 56.7 $\mathrm{MPa}$. Figure 8 shows the fracture morphology of the casting. For conventional HPDC samples (Fig. 8a), porosity exhibited at the fracture surface of the tensile specimen. At the vicinity of the porosity, the fracture surface was flat in morphology. 

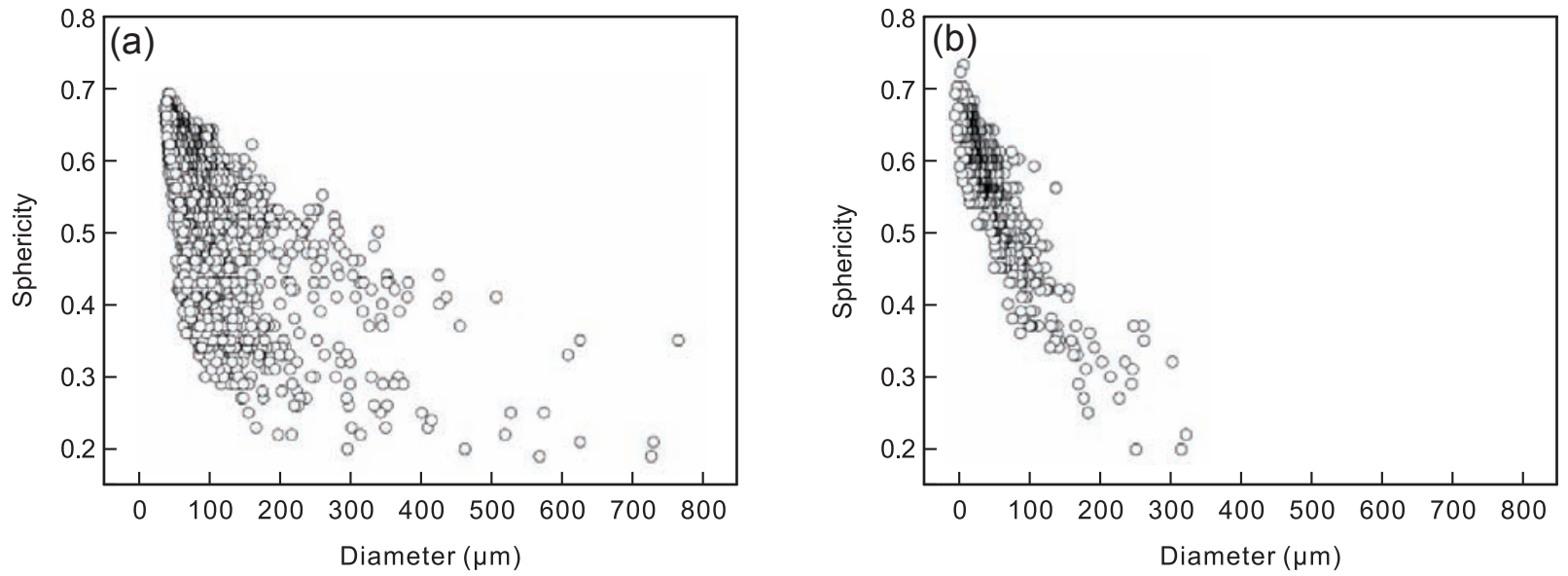

Fig. 6: Estimated sphericity versus the porosity diameter for conventional HPDC (a) and VADC (b)

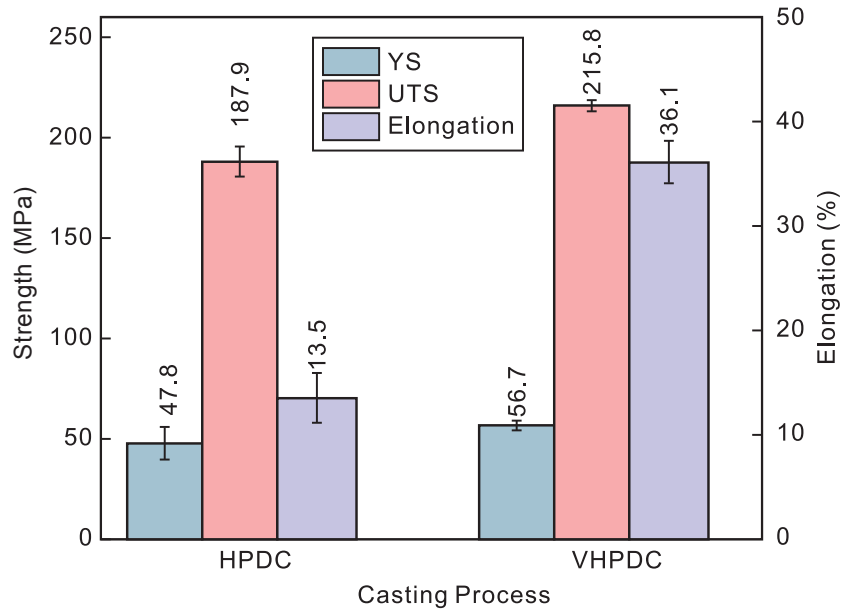

Fig. 7: Tensile testing results of two HPDC processes
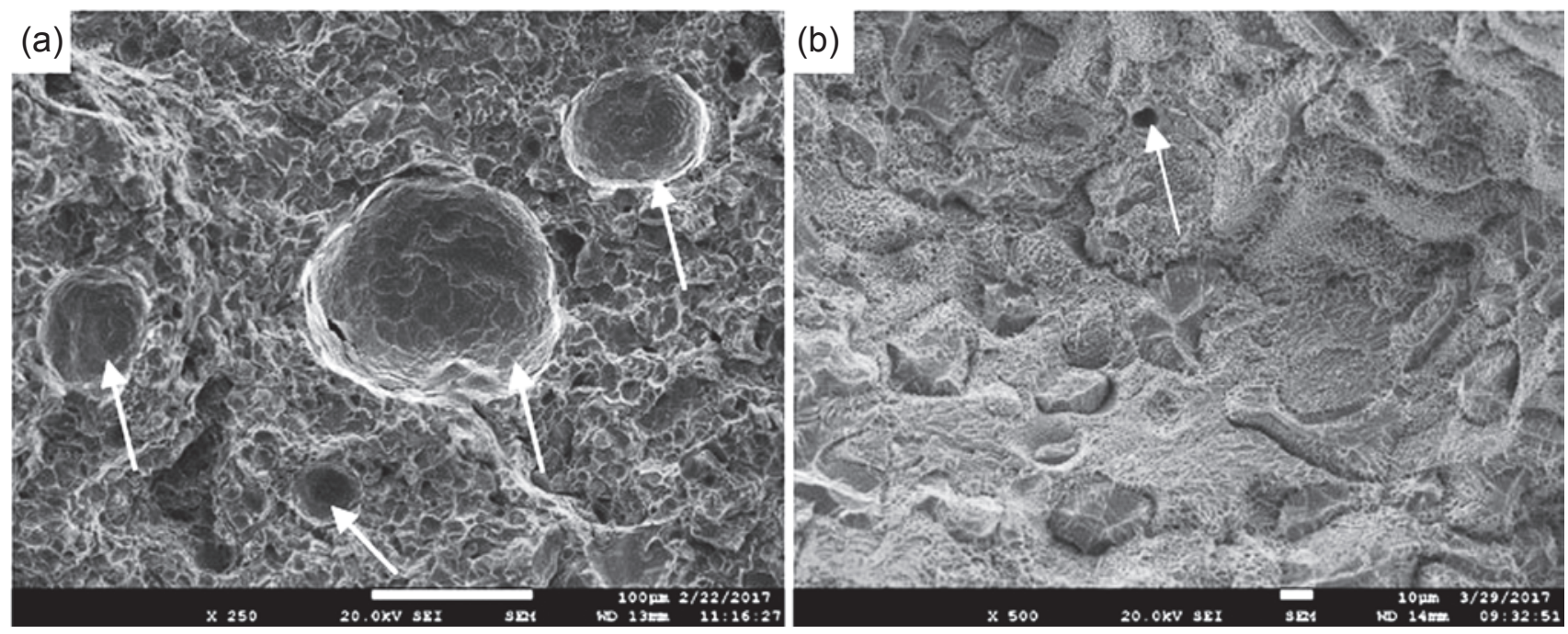

Fig. 8: High magnification SEM fractography of casting under conventional and vacuum-assist HPDC

by the volume fraction of the bulk porosity in HPDC AZ91D alloys. Lee et al. ${ }^{[7]}$ found that the variability in the ductility showed a quantitative correlation with the porosity fraction in the corresponding fracture surface.
The presence of porosity induced stress concentration and led to crack initiation. Song et al. ${ }^{[11]}$ found that the fracture occurred at areas with larger pores or cluster pores during tensile deformation. Jiang et al. ${ }^{[21]}$ simulated the fracture process and found that gas pores could connect with each other to form a microscopic crack. Pores also exhibited at the fracture surface of HPDC samples. The presence of the porosity resulted in brittle fracture, which led to crack initiation and propagation in the eutectic phase. Figure 8(b) shows that the fracture surface of VADC samples exhibited small dimples and shear fracture without porosity. Inter-granular and trans-granular fractures also exhibited. The presence of dimples with eutectics in microscopic void indicated ductile failure. This is consistent with those found in previous studies. Biswas et al. ${ }^{[12]}$ found that the tensile strength and elongation were strongly affected

\section{Conclusions}

The porosity of copper die-castings under conventional HPDC and VADC processes was characterized using metallography 
and X-ray computed tomography. Accordingly, the following conclusions can be drawn:

(1) Based on 2-D and 3-D morphology characterization, gas porosity, gas shrinkage porosity and shrinkage porosity were observed in high pressure die-cast pure copper.

(2) Comparing with conventional HPDC, the application of vacuum could reduce both number and size of porosity, including gas shrinkage and other shrinkage porosity. The average volume fraction of porosity decreased from $2.243 \%$ to $0.875 \%$.

(3)The application of the vacuum in HPDC improved the mechanical properties of copper castings. In particular, the ultimate tensile strength increased by $14.8 \%$, and the elongation increased from $13.5 \%$ to $36.1 \%$.

\section{References}

[1] Francesco P, Marco V. Design of high efficiency induction motors with die-casting copper rotors. Springer, Berlin, Heidelberg, 2003: 144-151.

[2] Dale T P, John G C, Edwin F B. Die casting copper motor rotors: Mold Materials and Processing for Cost-Effective Manufacturing, 2000.

[3] Dale T P, John G C, Edwin F B, et al. Performance of motors with die-cast copper rotors in industrial and agricultural pumping applications: IEEE International Conference on Electric Machines \& Drives, 2010: 987-992.

[4] Liang Dong, Yang Xu, Yu Jiabin, et al. Experience in China on the die-casting of copper rotors for induction motors. In: Proceedings-2012 20th International Conference on Electrical Machines, 2013: 256-260.

[5] Edwin F B, Stephen P M, Walkington W G, et al. Porosity control in copper rotor die castings. In: Proceedings of North American Die Casting Association Congress, Indianapolis, 2003.

[6] András B, Walter B. Two frequently development ways of induction motors: high efficiency and high-speed drives. 4th International Conference on Magnetism and Metallurgy, 2018: 387-391.

[7] Soon G L, Gautam R P, Gokhale A M. Quantitative fractographic analysis of variability in the tensile ductility of high-pressure die-cast AE44 Mg-alloy. Materials Science \& Engineering A, 2006, 427(1): 255-262.

[8] Soon G L, Gautam R P, Gokhale A M, et al. Variability in the tensile ductility of high-pressure die-cast AM50 Mg alloy. Scripta Materialia, 2005, 53(7): 851-856.
[9] Li Xiaobo, Xiong Shoumei. Correlation between porosity and fracture mechanism in high pressure die casting of AM60B alloy. Journal of Materials Science \& Technology, 2016, 32(1): 54-61.

[10] Song Jie, Xiong Shoumei, Li Mei, et al. The correlation between microstructure and mechanical properties of highpressure die-cast AM50 alloy. Journal of Alloys \& Compounds, 2009, 477(1): 863-869.

[11] Song Jie, Xiong Shoumei, Li Mei, et al. In situ observation of tensile deformation of high-pressure die-cast specimens of AM50 alloy. Materials Science \& Engineering A, 2009, 520(1): 197-201.

[12] Biswas S, Sket F, Molina C, et al. Relationship between the $3 \mathrm{D}$ porosity and beta-phase distributions and the mechanical properties of a high pressure die cast AZ91 Mg alloy. Metallurgical \& Materials Transactions A, 2013, 44(9): 43914403.

[13] Harshita A P, Rashidi N, Chen Daolun, et al. Cyclic deformation behavior of a super-vacuum die cast magnesium alloy. Materials Science \& Engineering A, 2012, 546(3): 72-81.

[14] Li Wan, Hu Zuqi, Wu Shusen, et al. Mechanical properties and fatigue behavior of vacuum-assist die cast AIMgSiMn alloy. Materials Science \& Engineering A, 2013, 576(8): 252-258.

[15] Niu Xiaoping, Hu Banghong, lan E P, et al. Vacuum assisted high pressure die casting of aluminium alloys. Journal of Materials Processing Technology, 2000, 105(1): 119-127.

[16] Li Xiaobo, Xiong Shoumei, Guo Zhipeng. Improved mechanical properties in vacuum-assist high-pressure die casting of AZ91D alloy. Journal of Materials Processing Technology, 2016, 231: 1-7.

[17] Wang Qingliang, Xiong Shoumei. Vacuum assisted highpressure die casting of AZ91D magnesium alloy at different slow shot speeds. Transactions of Nonferrous Metals Society of China, 2014, 24(10): 3051-3059.

[18] Yang Zhoufei, Maurey A, Kang Jidong, et al. 2D and 3D characterization of pore defects in die cast AM60. Materials Characterization, 2016,114: 254-262.

[19] Soon G Lee, Gokhale A M. Formation of gas induced shrinkage porosity in Mg-alloy high-pressure die-castings. Scripta Materialia, 2006, 55(4): 387-390.

[20] Cao Hanxue, Hao Mengyao, Shen Chao, et al. The influence of different vacuum degree on the porosity and mechanical properties of aluminum die casting. Vacuum, 2017, 146: 278281.

[21] Jiang Wei, Cao Zhanyi, Xu Sun, et al. Three-dimensional microstructure reconstruction and finite element simulation of gas pores in the high-pressure die-casting AZ91 Mg alloy. Microscopy \& Microanalysis, 2015, 21(6):1420-1425. 